\title{
Prevalence and Risk Factors of Hepatitis B and Hepatitis $C$ Virus Infections among Patients with Chronic Renal Failure in Zabeed City, Yemen Republic
}

\author{
Mohammed A. Al-Hegami1 , Abdullah Al-Mamari2*, Abdulrahman S. Al-Kadasse ${ }^{3}$, \\ Fadhl A. S. Al-Gasha'a ${ }^{4}$, Sadeq Al-Hag ${ }^{2}$, Adel A. S. Al-Hegami ${ }^{5}$ \\ ${ }^{1}$ Department of Science, Faculty of Education, Sana'a University, Sana'a, Yemen Republic \\ ${ }^{2}$ Department of Biological Sciences, Faculty of Science, Ibb University, Ibb, Yemen Republic \\ ${ }^{3}$ Department of Biological Sciences, Al-Hodeidah University, Al-Hodeidah, Yemen Republic \\ ${ }^{4}$ Department of Medical Microbiology, Faculty of Science, Ibb University, Ibb, Yemen Republic \\ ${ }^{5}$ Department of Internal Medicine, Faculty of Medicine, Sana'a University, Sana'a, Yemen Republic \\ Email: ${ }^{*}$ almamarynew@yahoo.co.in
}

Received 31 July 2015; accepted 15 September 2015; published 18 September 2015

Copyright (C) 2015 by authors and Scientific Research Publishing Inc.

This work is licensed under the Creative Commons Attribution International License (CC BY).

http://creativecommons.org/licenses/by/4.0/

(c) (i) Open Access

\section{Abstract}

Background and Aims: Patients on hemodialysis (HD) are at high risk of viral hepatitis due to high number of blood transfusion sessions, prolonged vascular access, high exposure to infected patients and contaminated equipment, or cross contamination from the dialysis circuits and pose problems in the management of patients in the renal dialysis units. This study was done to determine the prevalence of Hepatitis B virus (HBV) \& Hepatitis C virus (HCV), in patients on hemodialysis in Zabeed City, Yemen Republic, and address the major risk factors for transmission of these viruses among HD patients. Materials and Methods: In this cross-sectional study, during June, 2013 to October, 2014, a total of 243 chronic hemodialysis patients were tested. Patients were selected from many regions by cluster sampling from Zabeed public hospital, (hemodialysis center) in Zabeed City, Yemen Republic. A close ended and multiple choice-based questionnaires were completed and HBsAg and anti-HCV antibodies were assessed using third generation enzyme linked immunoassay kit as serological testing and data were analyzed using the SPSS-20 software. Results: The overall prevalence of positive HBsAg was $(48.83 \%)$ while positive anti-HCV was (46.01\%) and (5.16\%) mixed infection with HBV and HCV. Analysis of risk factors in patients with HBV \& HCV infection is showed the history of blood transfusion and duration of hemodialysis was found to be a statistically significant $(P<0.05)$ as risk factor for HBV and HCV infection. Conclusion:

\footnotetext{
${ }^{*}$ Corresponding author.
}

How to cite this paper: Al-Hegami, M.A., et al. (2015) Prevalence and Risk Factors of Hepatitis B and Hepatitis C Virus Infections among Patients with Chronic Renal Failure in Zabeed City, Yemen Republic. Open Journal of Medical Microbiology, 5, 136-142. http://dx.doi.org/10.4236/ojmm.2015.53017 
The evaluation suggests that blood transfusion and duration of hemodialysis may be the main most important risk factor for $\mathrm{HBV}$ and $\mathrm{HCV}$ infection among hemodialysis patients.

Keywords

HBV, HCV, Hemodialysis, Zabeed City, Yemen Republic

\section{Introduction}

Viral hepatitis has a special relationship to renal disease. Hepatitis B virus (HBV) and hepatitis C virus (HCV) infections are more prevalent in renal failure patients than in the general population [1]. Viral hepatitis is an important cause of morbidity and mortality of renal failure patients on chronic dialysis and after renal transplantation. The association between viral hepatitis and renal failure is largely due to the high number of blood transfusion session in patients with end-stage kidney disease and tothe multiple invasive medical procedures to which these patients are exposed [2]. These patients are often anemic, require prolonged vascular access, have high possibility of exposure to infected patients and contaminated equipment, and cross contamination from the dialysis circuits [1] [2]. Hemodialysis is a trusted intermediate procedure for management of chronic kidney disease (CKD) patients. CKD is an immune deficient state, hence blood borne viral infection particularly HBV and HCV are important cause of morbidity and mortality of patients treated by hemodialysis and if CKD patients are infected with HBV and HCV, it retards the post-transplant prognosis too [3]. Patients on hemodialysis may be infected through blood transfusions, contamination of dialysis machines and equipment's as well as interpersonal horizontal transmission in the dialysis units [4]. Blood transfusion has been correlated with an increase in HBV infection. The majority of cases with chronic HBV and/or HCV infection develop complications 15\% - 40\% may develop cirrhosis, liver failure and or hepatocellular carcinoma [3]-[5]. Hepatitis B virus (HBV) and hepatitis $\mathrm{C}$ virus (HCV) infections have wide range in prevalence rates in different regions of the world, ranging from $1 \%$ in the UK to more than $90 \%$ in Eastern Europe in hemodialysis patients [6]. In Arab countries, the prevalence of chronic HBsAg positivity among HD patients ranged from 2\% in Morocco, to 11.8\% in Bahrain [5]-[7]. Also in Arab countries the prevalence of HCV antibodies among HD patients has been reported to range from 27\% in Lebanon to $75 \%$ in Syria [6]-[8]. However there are strong indications that studies of HD patients which rely solely on serological screening could underestimate the prevalence of HCV infection [3]. From Center for Liver Research and Diagnostics, Hyderabad, India has reported that, among the patients of CKD and of either renal transplant or hemodialysis, $7 \%$ had HBV infection alone, $46 \%$ were infected with HCV alone. While, it is seen that the pooled prevalence of HBV infection among hemodialysis patients in China was $11.9 \%$ and HCV infection was $41.1 \%$ [9]. One of limitation's which faced this research no documented data or previous studies have been reported on the prevalence of hepatitis viruses among HD patients in Yemen and to the best of our knowledge this study is the first to address this issue. Therefore, the main objective of this study was to estimate the prevalence of HBV and HCV among HD patients in Zabeed City, Yemen Republic and address the major risk factors for transmission of these viruses among HD patients.

\section{Materials and Methods}

A cross sectional study was ducted on 243 chronic hemodialysis patients in Zabeed City during a period of June, 2013 to October, 2014. Patients were selected by cluster sampling from Zabeed public hospital, (hemodialysis center) in Zabeed City, Yemen Republic. Patients at range age 15 to 60 years and sex who were under hemodialysis treatment in studied hemodialysis center were eligible. Data collected included demographic information (age and sex), duration on hemodialysis, history of blood transfusion, and the number of transfused blood units as risk factors to HBV and HCV infections. A multiple choice questionnaire was completed by the researcher via patient interview to ensure proper data collection and prevent any misunderstanding. Patients, HBsAg and anti-HCV antibody status was investigated by serological testing. Five milliliters of blood was drawn from each patient in plain tube, prior to dialysis, to prevent the interference of heparin with downstream applications. HBsAg and anti-HCV antibodies were assessed using third generation enzyme linked immunoassay kit (ULTRA kit, bioMurieux, France). Data were analyzed using the SPSS-20 software. Variables were presented as Mean \pm 
SD and number (percent). Considering the number of HBsAg positive patients (six patients), nonparametric Mann-Whitney U test was used to compare the age, sex, time duration on hemodialysis and the number of transfused blood units. In patients with HCV positive, Independent t-test was used to compare the age and time duration on hemodialysis. In addition, sex and history of blood transfusion were assessed using Chi-square test for both HCV and HBV patients. P value less than 0.05 was considered to be statistically significant.

\section{Results}

All patients were affected with kidney failure. Total 213 out of 243 patients were attended the hemodialysis unit. Out of this 157 were males and 56 were females. Most of the patients were between 15 and 60 years of age and mean age was 46.16 years. The mean time duration on hemodialysis for all patients was $28.8 \pm 9.6$ months and 95 (39.3\%) of all patients had history of blood transfusion. The overall prevalence of positive HBV Ag was 104 patients (48.83\%) while positive anti-HCV was 98 patients (46.01\%) and 11 patients (5.16\%) had mixed infection with HBV and HCV among hemodialysis patients in studied population (Table 1).

The results of this study showed that the prevalence of HBV and HCV infection among males 87 (55.41\%) and $63(40.13 \%)$ respectively while in females was 17 (30.36\%) and $35(62.50 \%)$ respectively in patients on hemodialysis (Table 2).

The results of our study showed relationship between HBV, HCV and groups patients aged as shown in (Table 3) where, the positive patients showing the highest prevalence between the age of 15 and 55 years with HBV 50 (52.08\%) \& HCV 40 (41.67\%), while was low with the >55years 15 (55.56\%), 12 (44.44\%) respectively. The cumulative mean age of the both HBV and HCV positive hemodialysis patients were 44.09 years.

Analysis of risk factors in patients with HBV \& HCV infection are shown in (Table 4) positive history of blood transfusion was found to be a statistically significant $(\mathrm{P}<0.03)$ risk factor for HBV and HCV infection. The average number of blood transfusion units received was $17 \pm 7.53$ in HBV positive while $11 \pm 8$ in HCV positive. Duration of dialysis was significantly associated with risk of HCV infection. 213 out of 243 positive patients were studded in this study, the major primary renal diseases causing end stage of kidney disease (ESKD) patients included chronic nephritis (23.9\%), hypertension (12.7\%), diabetes mellitus (18.8\%), cystic renal diseases (6.6\%), urologic diseases (7.0\%), systemic lupus erythematous (SLE) (1.9\%) and nonspecific chronic pyelonephritis (6.1\%). There were (23.0\%) with unknown etiology (Figure 1).

Table 1. HBV and/or HCV sero-positivity in hemodialysis unit in Zabeed City.

\begin{tabular}{|c|c|c|c|c|c|c|c|c|c|c|c|}
\hline \multirow{3}{*}{$\begin{array}{l}\text { Name of city } \\
\text { (the residency } \\
\text { of patient) }\end{array}$} & \multirow{3}{*}{$\begin{array}{l}\text { Number of } \\
\text { tested patients }\end{array}$} & \multirow{2}{*}{\multicolumn{2}{|c|}{$\begin{array}{l}\text { Number of } \\
\text { non-infected } \\
\text { patients }\end{array}$}} & \multirow{2}{*}{\multicolumn{2}{|c|}{$\begin{array}{c}\text { Number of infected } \\
\text { patients }\end{array}$}} & \multicolumn{6}{|c|}{ Number of patients infected with hepatitis viruses } \\
\hline & & & & & & \multicolumn{2}{|c|}{$\begin{array}{l}\text { HBV-positive } \\
\text { patients }\end{array}$} & \multicolumn{2}{|c|}{$\begin{array}{l}\text { HCV-positive } \\
\text { patients }\end{array}$} & \multicolumn{2}{|c|}{$\begin{array}{l}\text { positive patients with } \\
\text { " } \mathrm{B}+\mathrm{C} \text { ” viruses }\end{array}$} \\
\hline & & Number & $\%$ & Number & $\%$ & Number & $\%$ & Number & $\%$ & Number & $\%$ \\
\hline Zabeed & 213 & 29 & 13.62 & 184 & 86.38 & 86 & 46.74 & 88 & 47.83 & 10 & 5.43 \\
\hline Raymah & 16 & 0 & 0.00 & 16 & 100.00 & 7 & 43.75 & 9 & 56.25 & 0 & 0.00 \\
\hline Sa'dah & 14 & 1 & 7.14 & 13 & 92.86 & 11 & 84.62 & 1 & 7.69 & 1 & 7.69 \\
\hline Total & 243 & 30 & 12.35 & 213 & 87.65 & 104 & 48.83 & 98 & 46.01 & 11 & 5.16 \\
\hline
\end{tabular}

Table 2. Gender distributionof HBV and/or HCV sero-positive among all hemodialysis patients.

\begin{tabular}{|c|c|c|c|c|c|c|c|c|c|c|c|}
\hline \multirow{3}{*}{ Sex } & \multirow{3}{*}{$\begin{array}{c}\text { Number of } \\
\text { tested patients }\end{array}$} & \multirow{2}{*}{\multicolumn{2}{|c|}{$\begin{array}{c}\text { Number of } \\
\text { non-infected patients }\end{array}$}} & \multirow{2}{*}{\multicolumn{2}{|c|}{$\begin{array}{l}\text { Number of infected } \\
\text { patients }\end{array}$}} & \multicolumn{6}{|c|}{ Number of patients infected with hepatitis viruses } \\
\hline & & & & & & \multicolumn{2}{|c|}{$\begin{array}{l}\text { HBV-positive } \\
\text { patients }\end{array}$} & \multicolumn{2}{|c|}{$\begin{array}{l}\text { HCV-positive } \\
\text { patients }\end{array}$} & \multicolumn{2}{|c|}{$\begin{array}{l}\text { positive patients with } \\
\text { "B + C" viruses }\end{array}$} \\
\hline & & Number & $\%$ & Number & $\%$ & Number & $\%$ & Number & $\%$ & Number & $\%$ \\
\hline Males & 182 & 25 & 13.74 & 157 & 86.26 & 87 & 55.41 & 63 & 40.13 & 7 & 4.46 \\
\hline Females & 61 & 5 & 8.20 & 56 & 91.80 & 17 & 30.36 & 35 & 62.50 & 4 & 7.14 \\
\hline Total & 243 & 30 & 12.35 & 213 & 87.65 & 104 & 48.83 & 98 & 46.01 & 11 & 5.16 \\
\hline
\end{tabular}




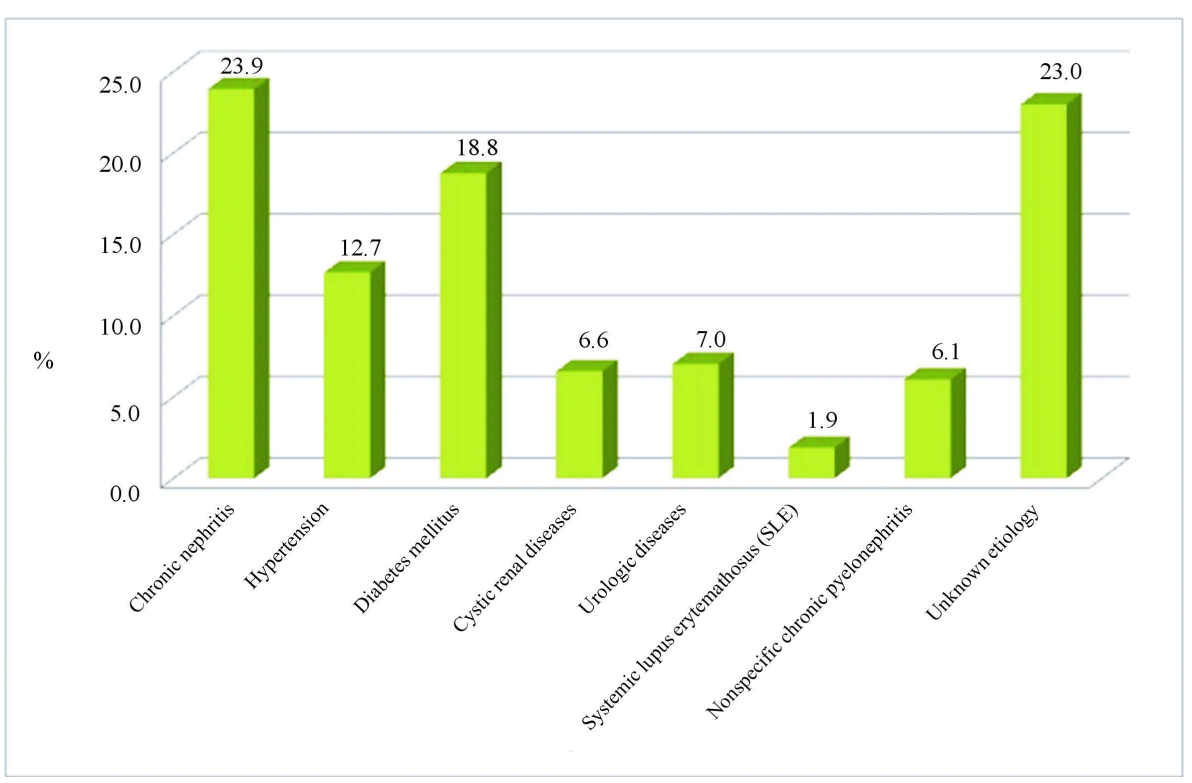

Figure 1. Etiology of prevalent regular HD patients.

Table 3. Frequency age distribution of HBV and/or HCV sero-positive hemodialysis patients.

\begin{tabular}{|c|c|c|c|c|c|c|c|c|c|c|c|}
\hline \multirow{3}{*}{$\begin{array}{c}\text { Age } \\
\text { (In Years) }\end{array}$} & \multirow{3}{*}{$\begin{array}{l}\text { Number of } \\
\text { tested patients }\end{array}$} & \multirow{2}{*}{\multicolumn{2}{|c|}{$\begin{array}{c}\text { Number of } \\
\text { non-infected patients }\end{array}$}} & \multirow{2}{*}{\multicolumn{2}{|c|}{$\begin{array}{c}\text { Number of } \\
\text { infected patients }\end{array}$}} & \multicolumn{6}{|c|}{ Number of patients infected with hepatitis viruses } \\
\hline & & & & & & \multicolumn{2}{|c|}{ HBV-positive patients } & \multicolumn{2}{|c|}{$\begin{array}{l}\text { HCV-positive } \\
\text { patients }\end{array}$} & \multicolumn{2}{|c|}{$\begin{array}{l}\text { positive patients with } \\
\text { "B + C" viruses }\end{array}$} \\
\hline & & Number & $\%$ & Number & $\%$ & Number & $\%$ & Number & $\%$ & Number & $\%$ \\
\hline $15-39$ & 111 & 15 & 13.51 & 96 & 86.49 & 50 & 52.08 & 40 & 41.67 & 6 & 6.25 \\
\hline $40-55$ & 100 & 10 & 10.00 & 90 & 90.00 & 39 & 43.33 & 46 & 51.11 & 5 & 5.56 \\
\hline$>55$ & 32 & 5 & 15.63 & 27 & 84.38 & 15 & 55.56 & 12 & 44.44 & 0 & 0 \\
\hline Total & 243 & 30 & 12.35 & 213 & 87.65 & 104 & 48.83 & 98 & 46.01 & 11 & 5.16 \\
\hline
\end{tabular}

Table 4. The risks factors potentially associated with HBV and/or HCV infection in hemodialysis unite inZabeed City.

\begin{tabular}{ccc} 
The risks factors & $\begin{array}{c}\text { HBV infected cases, } n \\
=104(48.83 \%)\end{array}$ & HCV infected cases, $n=98$ (46.01\%) \\
\hline Puration of dialysis in months (mean \pm SD) & $17 \pm 7.53$ & $11 \pm 8$ \\
Positive history of blood transfusion, $n=148(84.95 \%)$ & $137(93.04 \%)$ & $<0.02$ \\
Number of blood unit's transfusion & $3(0-6)$ & $0(0-2.7)$ \\
\hline
\end{tabular}

\section{Discussion}

It has been reported that hemodialysis increases the possibility of blood borne viral infection but the prevalence is variable from hemodialysis center to center, region to region and country to country and high-cost hemodialysis center vs low-cost hemodialysis center [10]. It is not well understood whether this variability has got any relationship with the basic prevalence of the disease in the community. In this study, the overall prevalence of positive HBsAg was (48.83\%) higher than, positive anti-HCV (46.01\%) and (5.16\%) had mixed infection with HBV and HCV among hemodialysis patients in studied population. The prevalence of HBV infection within dialysis units in developing countries appears higher (20\%) based on several reports. In another study, the overall prevalence of HBV in HD patients in Gaza strip was (8.1\%). This prevalence higher than in other neighboring countries like Jordan (5.9\%) and lower than others such as Saudi Arabia (10\%) and Bahrain (11.8\%) [5]-[9] [11]. A similar study conducted in India has reported high prevalence of $\mathrm{HBV}$ of $55 \%$ and $\mathrm{HCV}$ of $25.8 \%$ in patients 
with HD [12] [13], which are similar to the results of the present study. The HBV prevalence rate varies from one dialysis unit to another. The prevalence rate in Europe is reported to be $23 \%$ - 43\%, in USA 16\% - 18\%, in Tunisia 18\%, in France 2.2\%, in Russia 39\% - 50\%, and in South Africa 17\% [14].

Generally, more than half of the infected patients on dialysis become persistent, symptoms hepatitis B surface antigen (HBsAg) carriers without biochemical evidence of hepatitis [13]. In addition, the appearance of serological markers for HBV may be delayed by as long as 6 - 12 months. Some dialysis centers have reported outbreaks of fulminant HBV infection indicating that immunocompromised hosts, such as end stage kidney disease patients on dialysis, may develop severe disease from HBV infection [15]. In India, reported prevalence of HBV and HCV infection among hemodialysis patient is variable which agreement to the results of our study.

On the other hand, 14 Studies carried out in various centers worldwide among dialysis patients have shown a prevalence of HCV as 8\% - 36\% in North America, [16] 25\% - 39\% in South America, [17] 1\% - 36\% in Europe, [18] 17\% - 51\% in Asia, [4] 1.2\% - 10\% in New Zealand and Australia, [4] [16] and 7\% - 85\% in South Africa [2] have reported that among patients on hemodialysis 5.9\% were HCV positive while, $1.4 \%$ patients had HBV infection and 3.7\% had infection with HBV and HCV [12]. Chandra et al. have reported that among the patients of chronic kidney disease, renal transplant orhemodialysis, HBV, HCV and infection of both viruses were $7.46 \%$ and $37.10 \%$ respectively these results are not agreement to the results of our study [19]. Overall, the prevalence and incidence of HBV and HCV infections in HD patients reflects the prevalence of these infections in the general population, the quality of healthcare services in a community and the standards of infection control practices in HD units are related. The results of [20] study, showed that male hemodialysis patients had higher HBV prevalence, whereas [14] study showed that male hemodialysis patients had higher HCV prevalence. These results are in disagreement with the results of study [12]. The results of the present study showed that the prevalence of HBV and HCV infection between males was 87 (55.41\%) and 63 (40.13\%) respectively while, in females was, 17 (30.36\%) and 35 (62.50\%) respectively in patients on hemodialysis. The present study results show significant differences in regard to sex had higher in male than female between hemodialysis patients with HBV or HCV infection. In accord [12] [14] studies results which did not show significant differences in regard to age between hemodialysis patients with HBV or HCV infection compared with hemodialysis patients without HBV or HCV infection whereas, this does not comply with [21] study that reported a statistically significant relationship between HBV infection and age of the patients in a way that patients aged less than 40 years were found to be more susceptible to HBV than older patients. This observation is in agreement with a previous report from Libya showing that the highest prevalence of HCV antibodies was observed in HD patients aged 36 - 55 years [17]. These results are in agreement with the results of our study which showed statistically significant relationship was found between HBV and patients aged less than 40 years were found to be more susceptible than older patients. Other studies [9] [18] [21] have reported a higher prevalence of HBV or HCV sero-positivity in older patients and the reason for this difference in not clear. On the other hand, the prevalence and incidence of HBV was $(17 \pm 7.53$ month) and for HCV was $(11 \pm 8$ month) sero-positivity was statistically significant (P < 0.02 ) related to the length of time on HD. This is consistent with nosocomial transmission related to dialysis since longer duration of dialysis represents a longer period at risk of acquiring an infection. Similar observations have been reported by other authors [8] [9] [11]-[15]. Prevention of nosocomial transmission is of vital importance in Yemen Republic as HCV antiviral treatment is expensive and its availability is limited to only a few centers. A positive history of blood transfusions with HCV or HBV infection it was 11 (6.96\%) and 137 (93.04\%) respectively, $(\mathrm{P}<0.3)$ as well as the number of blood transfusions as risk factors was strongly associated with HBV or HCV infectionat baseline, but not with new infections $(\mathrm{P}<0.05)$. Prior to the introduction of effective screening of blood donors, blood transfusions were recognized as the leading source of HCV infection and some of these infections may have been acquired before adequate screening was introduced [21]. In addition it is possible that some blood donors with HCV infection are being missed by current screening procedures and these may need to be reassessed [4] [22]. On the other hand, the lack of association between blood transfusions and new infections suggests that fewer infections are acquired by this route than previously. A large proportion of patients had previously received blood transfusions. The risk of infection could therefore be further reduced by more effective management of anemia with iron supplementation and erythropoietin. In accordance with other studies [20], HBV or HCV infection was more prevalent in patients with a history of previous renal transplant. The major primary renal diseases in the end stage of kidney disease (ESKD) patients correlated with HCV or HBV it was included chronic nephritis (23.9\%), hypertension (12.7\%), diabetes mellitus (18.8\%), cystic renal diseases (6.6\%), urologic diseases (7.0\%), systemic lupus erythematous (SLE) (1.9\%) and nonspe- 
cific chronic pyelonephritis (6.1\%). There were (23.0\%) with unknown etiology. The prevalence of HCV antibodies in patients from nephrology units is high and has been reported to range from (5\% to $52 \%$ ) with $23.2 \%$ it was statistically significant.

One of limitation's which faced this research no documented data or previous studies have been reported on the prevalence of hepatitis viruses among HD patients in Yemen in additions to war conditions and most of facilities were not available.

\section{Conclusion}

The results of this study showed that the prevalence of HBV and HCV infections in hemodialysis center in Zabeed City is higher than some other countries. History of blood transfusion and the number of blood units transfused might be a risk factor for HBV and HCV gaining. However, further studies are needed to assess the role of other demographic and clinical risk factors in these patients. Urgent action is required to improve infection control measures in HD centers in Yemen republic and to reduce dependence on blood transfusions for the treatment of anemia.

\section{Acknowledgements}

The authors would like to express about their appreciation and deep gratitude to the staffs of hemodialysis center in Zabeed City and Al-Thawra and EL-Gomhory laboratories in Al-Hodeidah City for technical support.

\section{References}

[1] Al Hijazat, M. and Ajlouni, Y. (2008) Hepatitis B Infection among Patients Receiving Chronic Hemodialysis at the Royal Medical Services in Jordan. Saudi Journal of Kidney Diseases and Transplantation, 19, 260-267.

[2] Boulaajaj, K., Elomari, Y. and Elmaliki, B. (2005) Prevalence of Hepatitis C, Hepatitis B and HIV Infection among Hemodialysis Patients in Ibn-Rochd University Hospital, Casablanca. Néphrologie \& Thérapeutique, 1, $274-284$. http://dx.doi.org/10.1016/j.nephro.2005.06.012

[3] Chandra, M., Khaja, M.N. and Hussain, M.M. (2004) Prevalence of Hepatitis B and Hepatitis C Viral Infections in Indian Patients with Chronic Renal Failure. Intervirology, 47, 374-376.

[4] Dentico, P., Buogiorno, R. and Volpe, A. (1992) Prevalence and Incidence of Hepatitis C Virus (HCV) in Hemodialysis Patients: Study of Risk Factors. Clinical Nephrology, 38, 49-52.

[5] Elzouki, A., Esmeo, M., Samod, M., Abonaja, A., Alagi, B. and Daw, M. (2006) Prevalence of Hepatitis B, C and HIV Infection in Libya: A Population-Based Nationwide Seropepidemiological Study. Liver International, 26, 20.

[6] Reddy, G.A., Dakshinamurthy, K.V., Neelaprasad, P., Gangadhar, T. and Lakshmi, V. (2005) Prevalence of HBV and HCV Dual Infection in Patients on Haemodialysis. Indian Journal of Medical Microbiology, 23, 41-43. http://dx.doi.org/10.4103/0255-0857.13872

[7] Telaku, S., Zekaj, S., Avdijaj, Xh., Elezi, Y., Kuqi, Xh., Zylfiu, B., Rudhani, I., Hasanxhekaj, V. and Fejza, H. (2003) Prevalence of Hepatitis B and C Infection in Dialysis Patient in Kosova. The Turkish Journal of Gastroenterology, 14, 106.

[8] Oguchi, H., Miyasaka, M. and Tokunaga, S. (1992) Hepatitis Virus Infection (HBV and HCV) in Eleven Japanese Hemodialysis Units. Clinical Nephrology, 38, 36-43.

[9] Otedo, A.E., Mc'Ligeyo, S.O. and Okoth, F.A. (2003) Seroprevalence of Hepatitis B and C in Maintenance Dialysis in a Public Hospital in a Developing Country. South African Medical Journal, 93, 380-384.

[10] El-kader, Y., El-Ottol, A., Elmanama, A.A. and Ayesh, B.M. (2010) Prevalence and Risk Factors of Hepatitis B and C Viruses among Hemodialysis Patients in Gaza Strip, Palestine. Virology Journal, 7, 210. http://dx.doi.org/10.1186/1743-422X-7-210

[11] Qadi, A.A., Tamim, H., Ameen, G., Bu-Ali, A., Al-Arrayed, S., Fawaz, N.A. and Almawi, W.Y. (2004) Hepatitis B and Hepatitis C Virus Prevalence among Dialysis Patients in Bahrain and Saudi Arabia: A Survey by Serologic and Molecular Methods. American Journal of Infection Control, 32, 493-495. http://dx.doi.org/10.1016/j.ajic.2003.12.009

[12] Alavian, S.M., Bagheri-Lankarani, K., Mahdavi-Mazdeh, M. and Nourozi, S. (2008) Hepatitis B and C in Dialysis Units in Iran: Changing the Epidemiology. Hemodialysis International, 12, 378-382. http://dx.doi.org/10.1111/j.1542-4758.2008.00284.X

[13] Ozer, A., Yakupogullari, Y., Beytur, A., Beytur, L., Koroglu, M., Salman, F. and Aydogan, F. (2011) Risk Factors of Hepatitis B Virus Infection in Turkey: A Population-Based, Case-Control Study: Risk Factors for HBV Infection. He- 
patitis Monthly, 11, 263-268.

[14] Abu El Makarem, M.A., Abdel Hamid, M., Abdel Aleem, A., Ali, A., Shatat, M., Sayed, D., Deaf, A., Hamdy, L. and Tony, E.A. (2012) Prevalence of Occult Hepatitis B Virus Infection in Hemodialysis Patients from Egypt with or without Hepatitis C Virus Infection. Hepatitis Monthly, 12, 253-258. http://dx.doi.org/10.5812/hepatmon.5805

[15] Joukar, F., Besharati, S., Mirpour, H. and Mansour-Ghanaei, F. (2011) Hepatitis C and Hepatitis B Seroprevalence and Associated Risk Factors in Hemodialysis Patients in Guilan Province, North of Iran: HCV and HBV Seroprevalence in Hemodialysis Patients. Hepatitis Monthly, 11, 178-181.

[16] Zahedi, M.J., Moghaddam, S.D., Alavian, S.M. and Dalili, M. (2012) Seroprevalence of Hepatitis Viruses B, C, D and HIV Infection among Hemodialysis Patients in Kerman Province, South-East Iran. Hepatitis Monthly, 12, 339-343. http://dx.doi.org/10.5812/hepatmon.5969

[17] Santos, M.G., Danguilan, R.A., Que, E.T., Balmaceda, R.P. and Padilla, B.S. (1998) Prevalence of Hepatitis B and Hepatitis C in Hemodialysis Patients. Nephrology, 4, 101-104. http://dx.doi.org/10.1046/j.1440-1797.1998.d01-6.x

[18] Wang, C., Sun, J. and Zhu, B. (2010) Hepatitis B Virus Infection and Related Factors in Hemodialysis Patients in China-Systemic Review and Meta-Analysis. Renal Failure, 32, 1255-1264. http://dx.doi.org/10.3109/0886022X.2010.517354

[19] Fejza, H. and Telaku, S. (2009) Prevalence of HBV and HCV among Blood Donors in Kosova. Virology Journal, 13, 6-21.

[20] Te, H.S. and Jensen, D.M. (2010) Epidemiology of Hepatitis B and C Viruses: A Global Overview. Clinics in Liver Disease, 14, 1-21. http://dx.doi.org/10.1016/j.cld.2009.11.009

[21] Taal, M.W. and van Zyl-Smit, R. (2000) Hepatitis C Virus Infection in Chronic Hemodialysis Patients-Relationship to Blood Transfusions and Dialyzer Re-Use. South African Medical Journal, 90, 621-625.

[22] Almawi, W.Y., Qadi, A.A., Tamim, H., Ameen, G., Bu-Ali, A., Arrayid, S. and Abou Jaoude, M.M. (2004) Seroprevalence of Hepatitis C Virus and Hepatitis B Virus among Dialysis Patients in Bahrain and Saudi Arabia. Transplantation Proceedings, 36, 1824-1826. http://dx.doi.org/10.1016/j.transproceed.2004.07.019 